\title{
Recognizing and Mitigating the Negative Effects of Information Technology Use: A Systematic Review of Persuasive Characteristics in Information Systems
}

\author{
Liisa Kuonanoja ${ }^{(\bowtie)}$ and Harri Oinas-Kukkonen \\ University of Oulu, Pentti Kaiteran katu 1, 90570 Oulu, Finland \\ liisa.kuonanoja@oulu.fi
}

\begin{abstract}
Although information systems and technology have brought many benefits into people's everyday lives, not to mention society as a whole, they are also accompanied by negative consequences. For example, technostress, anxiety, and even different kinds of addictions are among the side effects of information technology use. Clearly, such negative consequences cannot be fully avoided, but at least some of them may be mitigated via good system design. In this study, we addressed the dark side of information technology use in everyday life and in a leisure context, reviewing contributions from the basket of eight information systems journals published between 2004 and early 2018. In our analysis, we utilized the Persuasive Systems Design model in order to recognize and analyze information system characteristics that may mitigate the negative consequences of information technology use.
\end{abstract}

Keywords: Dark side $\cdot$ Negative consequences $\cdot$ Persuasive technology Persuasive system design model

\section{Introduction}

In recent decades, the way we live and work has been revolutionized. Information systems (IS) have brought transformational benefits to individuals, organizations, and even society as a whole [1, p. 58]. However, these benefits have not come without a cost, which is the dark side of IS. With the increased use of information technology (IT), undesirable side effects are also increasing. Recognizing such negative consequences and making improvements to system design could help researchers to identify new ways to reduce the potential harm caused by IS. As yet, there is a lack of literature on this topic; however, some of the harmful and even damaging consequences of IS use have already been identified [2,3]. It is hoped that these consequences can be mitigated, if not prevented.

The negative effects of IS may be apparent at both individual and organizational levels, leading to negative societal effects on a large scale. For example, decreased job satisfaction as well as organizational and continuance commitment [4], anxiety [5], and problems with everyday life and social relations [6] are among the negative consequences of IT use. This paper focuses solely on negative effects at the individual level. 
Another group of negative consequences of IT usage may arise from users behaving maliciously toward others via IT [1, p. 178]. Examples of this include cyberbullying and the hacking of systems belonging to individuals or organizations. Such malicious actions, in which an individual comes to harm as a result of another person's conduct rather than from their use of IT per se, are beyond the scope of this paper.

In this study, we have focused on voluntary IT use for non-organizational purposes. The specific aim of this paper was to identify software features and qualities that may mitigate the negative consequences of IS that have been identified in the literature. We achieved this by analyzing published articles from major scientific journals in the IS field. ${ }^{1}$ The Persuasive Systems Design (PSD) model [7] has described a means for influencing IS users in a positive manner. We have argued that this model is a useful tool for determining which software features and qualities identified in earlier studies can be used in our research context. Thus, in this analysis, we utilized the PSD model as a lens through which to look at ways of mitigating the dark side of IT use.

\section{Background}

\subsection{The Dark Side of Information Systems}

The use of IT carries consequences for individuals and, eventually, for the whole of society. Although the benefits of technology are often emphasized, there are also many negative effects. The dark side of IT use has been defined by Tarafdar et al. [2] as "a broad collection of 'negative' phenomena that are associated with the use of IT, and that have the potential to infringe the well-being of individuals, organizations and societies." The first studies on these negative effects were conducted over 30 years ago, and they mostly focused on workplace and organizational contexts [2]. The scope of research has since broadened to include leisure IT use [3].

Naturally, new negative consequences will continue to arise as IT evolves. In a study by Pirkkalainen and Salo [3], the majority of negative consequences of IT use fell under four categories: technostress, IT addiction, IT anxiety, and information overload. Technostress is stress experienced by an end user of IT [4]. End users may experience technostress in organizational contexts as a result of using work-related information and communication technology (see, for example, [4]) or in leisure contexts as a result of using, for instance, social networking sites (see, for example, [8]). Information overload occurs when IT provides too much information in comparison to a user's needs, thus overwhelming the user [3, 9].

Addiction may be associated with different types of IS, such as games (for example, [10]), social networking sites (for example, [11, 12]), online auction sites, or, more broadly, mobile phones and the internet. According to one definition of IT addiction, it is "a psychological dependency on IT that involves excessive and compulsive use despite significant negative consequences" [14]. In contrast, IT anxiety concerns an individual's willingness and ability to use IT [15]. People suffering from IT anxiety may avoid using IT and may have difficulties understanding new technology. They may also feel

\footnotetext{
${ }^{1}$ http://aisnet.org/?SeniorScholarBasket
} 
apprehension when using IT [3]. There are also other kinds of negative consequences, such as loss of privacy and injuries related to poor ergonomics [2].

These consequences may impact individuals in many ways. Users may experience stress and their productivity may decrease [16], or they may become addicted to or obsessed with some element of IT, which could lead to obesity, decreased happiness, social isolation, and in the worst cases, even death [11]. It is evident that there is a need to find methods that mitigate the negative consequences of IT use.

\subsection{Persuasive Systems Design}

People often have a need to change aspects of their behavior or their attitudes, such as exercising more or using less plastic. Software design strategies used by persuasive technology can help people to change their attitudes or behavior [7]. According to the definition of persuasive technology, coercion and deception should not be used [7], rather the use of such systems should be voluntary in nature [17, 18]. Persuasive systems are often used in health-related systems, such as those that aid smoking cessation, or help individuals change their lifestyle in order to incorporate healthier habits $[18,19]$. Persuasive systems have also been utilized in other domains, such as e-commerce and energy conservation.

The PSD model by Oinas-Kukkonen and Harjumaa is a tool for designing and evaluating persuasive systems [7]. The model consists of three phases that guide the designer through the system design process:

- The first phase, known as persuasion postulates, explains the main issues behind persuasive systems that relate to behavior change and IT, which the designer should understand before creating a new system. First, there is an understanding that IT is never neutral but that it always affects users in one way or another. Second, a user's commitment and cognitive consistency are needed for the change. Third, persuasion may happen through direct or indirect routes, and the route that is more effective depends on users' personal characteristics and the persuasion situation. Fourth, incremental steps toward the target behavior should be supported, since change is usually easier to achieve by taking small steps. Fifth, persuasion should be open and transparent, and designer bias should be revealed. Sixth, it is important for the system to be unobtrusive, because disturbing a user at an inopportune moment may result in unwanted outcomes. Finally, seventh, the system should be useful and easy to use [7].

- The second phase of the PSD model [7] focuses on examining the persuasion context to gain a comprehensive understanding of the situation in which the persuasion event will take place. The intent of the persuader and the type of change the system is supporting (whether this is a user's behavior or attitude) should be analyzed. The use, user, and technology context should be given attention to form a rigorous picture of the persuasion event. In addition, the strategy incorporating the main message and the route of persuasion should be designed. A system designed with such understanding will be more persuasive and fitting for the targeted users [7].

- The third phase consists of determining which software features will support users in approaching their behavior change objective. In the PSD model, such features are 
divided into four categories, namely, primary task support, dialogue support, credibility support, and social influence. A new system does not need to incorporate all of these categories nor all of the features they contain, but their use will make it more persuasive [7]. The effects of software features have been investigated in numerous studies, such as $[19,20]$.

The factors mentioned in the PSD model are presented on a relatively abstract level, which leaves room for designers to interpret them. This means that the postulates can be taken into account and the chosen software system features can be implemented in a manner preferred by the design team.

\section{Methods}

As the basis for our research, we utilized a study previously carried out by Pirkkalainen and Salo [3], which was a literature review of the current state of dark side phenomena in IS that provided future directions for research. They concentrated their search on the basket of eight journals in IS research, because their objective was to focus on the main contributions to the IS field, which were likely to be in the field's leading journals [3]. ${ }^{2}$ The focus of their review was the negative effects of IT use on individuals in both leisure and organizational contexts. Searched material included all issues of the abovementioned journals from 1995 to 2015. Pirkkalainen and Salo [3] went through all journal issues without using a keyword search. Articles meeting the set criteria (studies addressing negative effect(s) of IT use on an individual) were included in their review.

In order to build on Pirkkalainen and Salo's [3] literature search, we used the same criteria in our study. We conducted a descriptive review [21] with a narrow scope in order to study our research objectives. We searched for articles issued between 2016 and early 2018, as these were published after the original research had been carried out. Contrary to Pirkkalainen and Salo [3], we concentrated only on articles investigating dark side effects in leisure contexts and excluded those in organizational contexts. As Pirkkalainen and Salo [3], we followed the main guidelines for literature review by Webster and Watson [22].

In the first round of our search, which was based on article titles, we found 39 new articles. We did not want to miss any relevant articles, so at this stage, we included articles about negative effects in organizational contexts. If an article was about the negative effects of IT use on individuals, then it was included, regardless of the context. After reviewing the abstracts and, if needed, the introductions, we included nine articles. To these, we added the 11 articles found by Pirkkalainen and Salo [3] relating to leisure/everyday contexts, bringing our data set to a total of 20 dark side articles.

\footnotetext{
${ }^{2}$ We utilized the basket of eight IS journals, which included the following top journals in the IS field: MIS Quarterly, Information Systems Research, Journal of Management Information Systems, Journal of the Association for Information Systems, European Journal of Information Systems, Information Systems Journal, Journal of Information Technology, and Journal of Strategic Information Systems. See: https://aisnet.org/?SeniorScholarBasket
} 
We extracted effective software system features and qualities from analyzed articles and categorized them according to the PSD model. We exploited all three phases of the PSD model, which we used as main categories. The first category was persuasion postulates, the second was the persuasion context (the intent, event, and strategy), and the third was persuasive system features (primary task support, computer-human dialogue, perceived credibility, and social support).

Our objective was to identify software features and qualities that mitigated the negative consequences of IS use. We included features that provoked negative consequences in order to raise awareness of their need for mitigation. Of the 20 articles in our data set, 14 contained features that had some effect on the consequences of IS use. At this stage, we excluded six articles, as they did not discuss the three abovementioned phases but investigated, for example, users' feelings and qualifications (for example, [23]), or measured users' technostress reactions [24]. These six articles were not within the scope of our review.

\section{Results}

Our analysis of the dark side of IT use revealed meaningful findings. A summary of these findings has been presented in Table 1. Some of the postulates indicating the main issues behind persuasion systems had important mitigating effects on the negative consequences of IT use. The next biggest category with an effect was social support. In this category, features had negative consequences on IT users, although in one paper, social features were found to have a mitigating effect.

Table 1. Summary of effective system features and qualities categorized according to the PSD model [cf. 7]

\begin{tabular}{l|l|l|l}
\hline PSD model & & Negative effects & Mitigation effects \\
\hline $\begin{array}{l}\text { 1. Persuasion } \\
\text { postulates }\end{array}$ & Unobtrusiveness & - & $\begin{array}{l}\text { System should not } \\
\text { interrupt the user [9] } \\
\text { Alert messages should not } \\
\text { interrupt a user's primary } \\
\text { task [27] }\end{array}$ \\
\cline { 2 - 4 } & $\begin{array}{l}\text { Usefulness and } \\
\text { ease of use }\end{array}$ & $\begin{array}{l}\text { Usefulness and ease of } \\
\text { use, among other related } \\
\text { factors, were antecedents } \\
\text { for addiction [14] }\end{array}$ & $\begin{array}{l}\text { Systems that are complex } \\
\text { and change often cause } \\
\text { stress [8] } \\
\text { Systems should not } \\
\text { require too much effort or } \\
\text { be deceptive [9] } \\
\text { When a user feels the } \\
\text { system will be useful and } \\
\text { easy to use, their attitude } \\
\text { toward it is positive [15] } \\
\text { Systems should have the } \\
\text { appropriate number of }\end{array}$ \\
\hline
\end{tabular}


Table 1. (continued)

\begin{tabular}{|c|c|c|c|}
\hline & & & $\begin{array}{l}\text { features for each type of } \\
\text { user [25] } \\
\text { Systems should guide a } \\
\text { user to help them find } \\
\text { relevant information [26] } \\
\text { Performance failures } \\
\text { should be avoided [28] }\end{array}$ \\
\hline \multirow{3}{*}{$\begin{array}{l}\text { 2. Persuasion } \\
\text { context }\end{array}$} & Intent & - & - \\
\hline & Event & & $\begin{array}{l}\text { Systems should fit into } \\
\text { users' lives [8] } \\
\text { A user's skills should be } \\
\text { taken into account during } \\
\text { system design [25] } \\
\text { New technology should } \\
\text { be well understood, before } \\
\text { implementing in order to } \\
\text { avoid failures [28] } \\
\text { Systems should work as } \\
\text { promised [31] }\end{array}$ \\
\hline & Strategy & - & - \\
\hline \multirow[t]{4}{*}{$\begin{array}{l}\text { 3. Persuasive } \\
\text { system } \\
\text { features }\end{array}$} & $\begin{array}{l}\text { Primary task } \\
\text { support }\end{array}$ & - & $\begin{array}{l}\text { Parental monitoring may } \\
\text { prevent addiction [10] } \\
\text { Self-monitoring may } \\
\text { decrease addiction [14] }\end{array}$ \\
\hline & $\begin{array}{l}\text { Computer- } \\
\text { human dialogue }\end{array}$ & $\begin{array}{l}\text { If systems are visually } \\
\text { attractive, then they may } \\
\text { be more addictive [14] }\end{array}$ & $\begin{array}{l}\text { Education and } \\
\text { suggestions may prevent } \\
\text { addiction [10] } \\
\text { Reminders and feedback } \\
\text { may prevent addiction } \\
{[14]}\end{array}$ \\
\hline & $\begin{array}{l}\text { Perceived } \\
\text { credibility }\end{array}$ & - & - \\
\hline & Social support & $\begin{array}{l}\text { Social features may make } \\
\text { systems more addictive } \\
{[11,10,14,29]} \\
\text { Social facilitation may } \\
\text { increase feelings of } \\
\text { loneliness [30] } \\
\text { Subjective norms } \\
\text { regarding social } \\
\text { networking site usage } \\
\text { increase users' feelings of } \\
\text { guilt and discontinuance } \\
\text { intentions [32] }\end{array}$ & $\begin{array}{l}\text { Recognition by others } \\
\text { may decrease users' } \\
\text { feelings of loneliness [30] }\end{array}$ \\
\hline
\end{tabular}


Of the 14 studies included in this review, nine described mitigation related to postulates in the PSD model [7]. The postulate stating that systems should be both useful and easy to use (including lack of errors and high quality information), was the most common mitigating quality. For example, Saunders et al. [25] mentioned that older users of mobile phones felt more easily overwhelmed by phones with a multitude of features compared to younger users. This finding is in line with suggestions made by the PSD model that systems should be easy to use and that designers should analyze the persuasion event to understand the user context.

In addition to system features, Vaghefi et al. [14] found characteristics of users themselves that made them more prone to IT addiction. In their study, a system's ease of use and its usefulness, among other features, were antecedents for IT addiction among users with certain characteristics. This postulate related to the impact of information scent and time constraints on users' stress, performance, and attitude [26]. Information scent is the collection of audio, visual, and semantic cues that guides users to the information they are seeking, making a system easy to use and positively influencing its performance.

The postulate stating that a system should be unobtrusive and should not disturb a user when s/he is performing a primary task arose in two of the studies, namely those by Cenfetelli and Schwarz [9] and Jenkins et al. [27]. The former [9] concerned six inhibitors that may prevent people from using a website. Among the inhibitors that had a negative consequence was intrusiveness, which was a quality of systems that interrupted users with unrequested tasks. Jenkins et al. [27] studied how interrupting a user with security messages affected their secondary task. They found that if a user was performing a primary task when they were interrupted by the security message, then they often disregarded the message. Thus, the message not only interrupted users' primary tasks but also their secondary task (the security issue to which the message referred), which may be neglected.

Some studies in this review, namely [8, 9, 25, 27, 28], identified features that designers should avoid if they wish to increase the likelihood of system use. Maier et al. [8] identified and examined features that created social networking stress, which had a significant effect on individuals' intention to discontinue use of the system. Of the six features that created stress [8], some could be categorized using the PSD model, because they discussed the same issues as the postulate regarding ease of use and usefulness. For example, system features that created stress included the complexity and constant changes of social networking systems. The work of Cenfetelli and Schwarz [9] followed the same line. Tan, Benbasat, and Cenfetelli [28] found that e-service failures had a negative effect on customer expectations.

Another category that stood out from the results was social support. The features in this category often had negative consequences for IT users, for instance, they increased the addictive influence of IS (see, for instance, [10, 11, 29]) and increased feelings of loneliness [30]. Social features had a negative impact on users in all four studies that explored IT addiction from different perspectives. Social enhancement (the value of online social networks to users based on their perception of other members' acceptance and approval of them), envy (the emotion social network users feel when they desire the possessions or life experiences of other users), and a feeling of missing out on social events and announcements, also known as FOMO, which arises if users do not 
frequently monitor social networking systems) had significant effects on the addictive use of social networking sites [11].

In their study on addiction to mobile social applications, Kwon et al. [29] suggested that social applications are designed to increase social liquidity, which they defined as "the ease with which one can establish interpersonal relationships" but also as "the number of users available with whom social relationships can be cultivated." They concluded that when a person is more sensitive to social liquidity, s/he is more vulnerable to mobile social application addiction. Vaghefi et al. [14] found that some social support features affected an individual's tendency toward IT addiction, namely connectivity and access to all communication channels. In online gaming addiction, $\mathrm{Xu}$ et al. [10] recognized several social factors that increased addictive behavior, which were a need for relationships and system features that supported socializing.

Matook et al. [30] discovered that the type of social system feature could determine whether it had positive or negative influences on users' feelings of loneliness. Passive features, whereby users passively consume the content of other users, such as photos or status updates, increased their feelings of loneliness. In contrast, active social system features, whereby users broadcast their own content to friends and followers, decreased their feelings of loneliness.

We identified system features effective in mitigating the negative consequences of IT use also from other categories of the PSD model [7], namely event, primary task support, and dialogue support features. Event features were mainly concerned with knowing and understanding the use, user, and technology contexts. For example, Saunders et al. [25] showed that systems designed to take different kinds of users into account, like those that provided a choice of basic or expert profiles, were less likely to cause stress. Vaghefi et al. [14] suggested that system features like usage reports (primary task support) and reminders (dialogue support) could help users to understand that their use of a system may not be totally under their control, which could mitigate its addictiveness.

In a case described by Salo and Frank [31], effects were more complicated. They studied the relationship between situational context and users' behavior after positive and negative critical incidents occurred with a mobile application. When a negative incident took place indoors, it led to negative word-of-mouth, which was not the case when it happened outdoors. When a negative incident occurred with a mobile application that had a physical aspect (that is, it required concrete interaction between the user and his/her mobile phone), users discontinued their system use more easily than after negative incidents relating to other kinds of systems. They concluded that systems should work as promised to prevent users from discontinuing their use. This fits with the PSD model's idea of understanding the technology context, especially as new technologies may not work as intended, which makes users more likely to stop using them. 


\section{Discussion}

As the first postulate of the PSD model [7] states, IT is never neutral, as it will always influence users' behavior and attitudes in one way or another. This was evident in the findings of articles included in this review. Naturally, as we focused on articles about the dark side of IT use, effects on users were often negative. However, articles also revealed ways to mitigate negative consequences, although further studies are needed to investigate e.g. how changing context affects.

As a category, social features were clearly the most important in terms of causing negative consequences. They may cause, for example, stress, envy, addiction, feelings of loneliness, and other issues. In only one study were social features found to have a mitigating effect on a negative issue, which was users' feelings of loneliness. In general, social features can have many positive effects, for example, during health behavior change [33], but as this review shows, they also have a dark side. Social features should still be used in IT, but system designers should find ways to mitigate and prevent their negative effects. For example, it may be useful to remind users that one cannot see the whole picture of others' lives through IT.

The need for social features and how they are utilized should be considered carefully by software designers. In some systems, social features may be highly beneficial from a user's point of view, but this is not so in all cases. For example, a persuasive system supporting a user to become more active should be careful in sending repeated requests for the user to share their activities with others. It may well be that they do not wish to do so.

Multiple mitigating characteristics were found in our review. Most of them can be categorized within the postulates of the PSD model [7]. The postulate concerning a system's usefulness and ease of use came up most often among the studies we reviewed. This postulate is rather broad and covers many qualities of a good information system, so this finding was not very surprising. However, it was somewhat surprising that ideas relating to a system's ease of use and usefulness were still so dominant in the analyzed literature. In the IS field, these two concepts have been under investigation for decades, and their importance is clear. However, in practice, it still seems to be rather difficult to prevent systems from causing unnecessary negative consequences to users.

As mentioned above, five studies investigated negative qualities of systems that should be avoided in order to mitigate the negative consequences of IT use. If a system has errors, does not function as promised, or if it requires too much effort from users, their feelings toward the system are likely to be negative. In the modern era, with everincreasing work and life demands on individuals and numerous information systems and applications available, there is no place for poorly functioning or excessively demanding systems in a leisure context.

If a system keeps changing its user interface without giving users enough time to adapt to the changes, they may stop using the system [8]. This finding is interesting, as it conflicts with the current trend of constantly modifying information systems. The frequency at which systems change, especially in relation to their user interfaces, should be carefully considered, as too many changes in a short period of time may 
cause users to leave rather than keeping them interested. Constant changes may cause stress, which may outweigh the benefits a system can deliver to users. This topic requires more research, especially in relation to different user groups.

Simplicity could be a good term to describe a system with few negative consequences for users. Systems should be easy for different kinds of users to learn and use. Depending on the system, there could be an option for users to choose different interfaces based on their skills; experienced users could use an advanced version offering a large number of features. Testing systems throughout the design and implementation phases and gathering feedback and use data from released systems could help to refine them to enhance the way they fit with users' lives.

Negative consequences of IT use can range from loss of productivity and stress [2, $3,16]$ to depression and loneliness [14]. Minor negative consequences might constitute short-term negative feelings, such as annoyance or irritation, which may disappear by themselves over time. Although undesirable, it may be too costly to mitigate these kinds of minor negative consequences completely. Individuals are all different, so there is no way to create a system that would avoid causing negative emotions to every user.

However, major negative consequences that cause harm not just on the individual level but also on the societal level need special attention. Addiction to IT is one of the most severe negative consequences of IS use. In this analysis, features that mitigated IT addiction were usage monitoring and giving feedback. These features were suggested by authors and were not tested for effectiveness. The effectiveness of usage monitoring, whether by a parent, as in the case of adolescent gaming addictions [10], or in the form of self-monitoring, is an open issue that needs to be investigated in different settings. In any case, if users notice and think about their negative behavior early enough by selfmonitoring and comparing their own use with that of others, then they could avoid addiction.

The analysis we have presented in this paper has some limitations. First, because our literature review included only studies from the basket of eight journals in the IS field, studies of the negative consequences of IT use outside of these journals were not analyzed. The number of articles we analyzed was therefore relatively low. However, the studies published in the journals we searched can be argued to represent the best research in the IS field. In addition, our review did not consider organizational contexts, which could be included in future studies to present a more complete picture of current research into features of IT use that mitigate its negative consequences. In spite of the limitations of this analysis, we were able to identify numerous gaps in knowledge in the studied area.

\section{Conclusion}

Information systems, regardless of their numerous benefits, also have negative effects on users and society. In this study, we analyzed previous research literature using the PSD model to identify system characteristics that could mitigate the negative effects of IT use. Most of the mitigating effects we identified in this review related to a system's usefulness and ease of use. In addition, systems that were unobtrusive and free from errors mitigated the negative consequences of IT use. Systems may cause negative 
feelings and consequences if they have many errors or if they are intrusive and disrupt users' primary tasks. Negative consequences of IT use can also be avoided or mitigated by understanding users and the context in which systems are used.

The features in the social support category were the primary cause of negative consequences in the studies we analyzed in this review. In some cases, they were found to cause, among other negative consequences, envy, loneliness, and addiction. However, in one dark side study, social features (that is, broadcasting to friends and followers) had a positive effect, as they reduced users' feelings of loneliness. Further research of social features in more specific contexts is needed to determine the further positive effects they might have on users and how they might mitigate the negative consequences of IT use. In one study in this review, reminders and self-monitoring were suggested as ways for users to avoid addiction to social networking applications.

The dark side of IT use is an issue that needs our attention. To find ways to mitigate the negative consequences of IT use, we first need to identify them. In this review, we compiled system characteristics from eight top IS journals that could mitigate the negative consequences of IT use. A system's ease of use and usefulness were valuable assets in this context. More research is needed to find other ways to mitigate the negative consequences of everyday IT use.

\section{References}

1. Oinas-Kukkonen, H., Oinas-Kukkonen, H.: Humanizing the Web: Change and Social Innovation. Palgrave Macmillan, Basingstoke (2013)

2. Tarafdar, M., Gupta, A., Turel, O.: Special issue on 'dark side of information technology use': an introduction and a framework for research. Inf. Syst. J. 25(3), 161-170 (2015)

3. Pirkkalainen H., Salo, M.: Two Decades of the Dark Side in the Information Systems Basket: Suggesting Five Areas for Future Research. In: Proceedings of the European Conference on Information Systems (ECIS) (2016)

4. Ragu-Nathan, T.S., Tarafdar, M., Ragu-Nathan, B.S., Tu, Q.: The consequences of technostress for end users in organizations: conceptual development and empirical validation. Inf. Syst. Res. 19(4), 417-433 (2008)

5. Sapacz, M., Rockman, G., Clark, J.: Are we addicted to our cell phones? Comput. Hum. Behav. 57, 153-159 (2016)

6. Seo, H.A., Chun, H.Y., Jwa, S.H., Choi, M.H.: Relationship between young children's habitual computer use and influencing variables on socio-emotional development. Early Child. Dev. Care 181(2), 245-265 (2011)

7. Oinas-Kukkonen, H., Harjumaa, M.: Persuasive systems design: key issues, process model, and system features. Commun. Assoc. Inf. Syst. 24(1), 485-500 (2009)

8. Maier, C., Laumer, S., Weinert, C., Weitzel, T.: The effects of technostress and switching stress on discontinued use of social networking services: a study of Facebook use. Inf. Syst. J. 25(3), 275-308 (2015)

9. Cenfetelli, R.T., Schwarz, A.: Identifying and testing the inhibitors of technology usage intentions. Inf. Syst. Res. 22(4), 808-823 (2011)

10. Xu, Z., Turel, O., Yuan, Y.: Online game addiction among adolescents: motivation and prevention factors. Eur. J. Inf. Syst. 21(3), 321-340 (2012) 
11. James, T.L., Lowry, P.B., Wallace, L., Warkentin, M.: The effect of belongingness on obsessive-compulsive disorder in the use of online social networks. J. Manage. Inf. Syst. 34 (2), 560-596 (2017)

12. Turel, O., Qahri-Saremi, H.: Problematic use of social networking sites: antecedents and consequence from a dual-system theory perspective. J. Manage. Inf. Syst. 33(4), 1087-1116 (2016)

13. Turel, O., Serenko, A., Giles, P.: Integrating technology addiction and use: an empirical investigation of online auction users. MIS Q. 35(4), 1043-1061 (2011)

14. Vaghefi, I., Lapointe, L., Boudreau-Pinsonneault, C.: A typology of user liability to IT addiction. Inf. Syst. J. 27(2), 125-169 (2017)

15. Pramatari, K., Theotokis, A.: Consumer acceptance of RFID-enabled services: a model of multiple attitudes, perceived system characteristics and individual traits. Eur. J. Inf. Syst. 18 (6), 541-552 (2009)

16. Tarafdar, M., D’Arcy, J., Turel, O., Gupta, A.: The dark side of information technology. MIT Sloan Manage. Rev. 56(2), 60-70 (2015)

17. Karppinen, P., Oinas-Kukkonen, H.: Three approaches to ethical considerations in the design of behavior change support systems. In: Berkovsky, S., Freyne, J. (eds.) PERSUASIVE 2013. LNCS, vol. 7822, pp. 87-98. Springer, Heidelberg (2013). https://doi.org/10.1007/ 978-3-642-37157-8_12

18. Torning, K., Hall, C., Oinas-Kukkonen, H.: Persuasive system design: state of the art and future directions. In: Chatterjee, S., Parvati, D. (eds.) Fourth International Conference on Persuasive Technology, ACM International Conference, vol. 350, Article no. 30. ACM, New York

19. Karppinen, P., Oinas-Kukkonen, H., Alahäivälä, T., Jokelainen, T., Keränen, A.-M., Salonurmi, T., Savolainen, M.: Persuasive user experiences of a health behavior change support system: a 12-month study for prevention of metabolic syndrome. Int. J. Med. Inform. 96, 51-61 (2016)

20. Lehto, T., Oinas-Kukkonen, H.: Explaining and predicting perceived effectiveness and use continuance intention of a behaviour change support system for weight loss. Behav. Inf. Technol. 34(2), 176-189 (2014)

21. Paré, G., Trudel, M.C., Jaana, M., Kitsiou, S.: Synthesizing information systems knowledge: a typology of literature reviews. Inf. Manage. 52(2), 183-199 (2015)

22. Webster, J., Watson, R.T.: Analyzing the past to prepare for the future: writing a literature review. MIS Q. 26(2), xiii-xxiii (2002)

23. Turel, O.: Quitting the use of a habituated hedonic information system: a theoretical model and empirical examination of Facebook users. Eur. J. Inf. Syst. 24, 431-446 (2015)

24. Tams, S., Hill, K., Thatcher, J.: NeuroIS - alternative or complement to existing methods? Illustrating the holistic effects of neuroscience and self-reported data in the context of technostress research. J. Assoc. Inf. Syst. 15(10), 723-753 (2014)

25. Saunders, C., Wiener, M., Klett, S., Sprenger, S.: The impact of mental representations on ICT-related overload in the use of mobile phones. J. Manage. Inf. Syst. 34(3), 803-825 (2017)

26. Moody, G.D., Galletta, D.F.: Lost in cyberspace: the impact of information scent and time constraints on stress, performance, and attitudes online. J. Manage. Inf. Syst. 32(1), 192-224 (2015)

27. Jenkins, J., Anderson, B., Vance, A., Kirwan, B., Eargle, D.: More harm than good? How messages that interrupt can make us vulnerable. Inf. Syst. Res. 27(4), 880-896 (2016)

28. Tan, C.-W., Benbasat, I., Cenfetelli, R.T.: An exploratory study of the formation and impact of electronic service failures. MIS Q. 40(1), 1-29 (2016) 
29. Kwon, H.E., So, H., Han, S.P., Oh, W.: Excessive dependence on mobile social apps: a rational addiction perspective. Inf. Syst. Res. 27(4), 919-939 (2016)

30. Matook, S., Cummings, J., Bala, H.: Are you feeling lonely? the impact of relationship characteristics and online social network features on loneliness. J. Manage. Inf. Syst. 31(4), 278-310 (2015)

31. Salo, M., Frank, L.: User behaviours after critical mobile application incidents: the relationship with situational context. Inf. Syst. J. 27(1), 5-30 (2017)

32. Turel, O.: Untangling the complex role of guilt in rational decisions to discontinue the use of a hedonic information system. Eur. J. Inf. Syst. 25(5), 432-447 (2016)

33. Laranjo, L., Arguel, A., Neves, A.L., Gallagher, A.M., Kaplan, R., Mortimer, N., Mendes, G.A., Lau, A.Y.S.: The influence of social networking sites on health behavior change: a systematic review and meta-analysis. J. Am. Med. Inform. Assoc. 22(1), 243-256 (2014) 